\title{
There are no Bitcoins, Only Bit Payers: Law, Policy and Socio-Economics of Virtual Currencies
}

\begin{abstract}
By Michael P. Malloy*
This paper explores the legal character of the Bitcoin and other emerging "virtual currencies," and the legal and policy implications of Bitcoin trading. It observes that these "cryptocurrencies" exhibit different legal characteristics depending on the context in which they are examined - whether transactional law, tax law, or criminal law, for example. The paper argues that the appropriate legal analogue for classifying Bitcoins should be investment and commercial notes, since this characterisation would lead to the application of an appropriate and effective body of transactional and regulatory law to Bitcoins.
\end{abstract}

\section{Introduction}

Over the past year, there has been an explosion of interest - and a frenzied up-swing in trading - in Bitcoins. ${ }^{1}$ From a socio-economic perspective, this offers an unusual opportunity to observe the emergence and development of an entirely new, and so far unregulated, kind of market. Scholars interested in the law and policy of financial services regulation are also presented with an important opportunity to test assumptions that we blithely make about the ways in which regulation interacts with business and commercial activity. ${ }^{2}$ Policymakers may confront a moment of truth - to regulate or not to regulate, and when, and how.

What is particularly worrisome about these questions is that the United States has a long history of awaiting financial disaster before instituting regulatory measures or basic reforms. Indeed, the history of federal legislation concerning bank regulation and supervision is essentially a seismographic record of every major financial crisis in the nation's history. ${ }^{3}$

\footnotetext{
"Distinguished Professor and Scholar, University of the Pacific McGeorge School of Law, USA.

${ }^{1}$ More than a hundred virtual currencies exist as of this writing, with the largest capitalised virtual currency, and the one that historically has received the lion's share of attention from investors and users, being Bitcoin. Kessler (2014).

${ }^{2} C f$. e.g. Turbeville (2013) (offering masterful critique and reconception of predominant approach to measuring efficiency in relation to evaluation of costs and benefits of regulation).

${ }^{3}$ See, e.g., Malloy (2011a) at 26-28 (providing graphic representation of modern developments in U.S. bank regulation).
} 
One can only hope that the record might be different this time. The Financial Crimes Enforcement Network (FinCEN) of the U.S. Treasury Department has in fact been addressing these issues since 2011, when it amended definitions and other regulations relating to money services businesses, among other things, to refine the definitions of dealers in foreign exchange and money transmitters, ${ }^{1}$ and to amend regulations relating to prepaid access to currency. ${ }^{2}$ In March 2013, it issued its own interpretive guidance to clarify that certain activities involving "convertible" cryptocurrencies as media of money transmission may be subject to the Bank Secrecy $\mathrm{Act}^{3}$ and the FinCEN regulations. ${ }^{4}$ Firms that create, obtain, distribute, exchange, accept, or transmit virtual currencies may be subject to FinCEN's registration, reporting, and recordkeeping requirements. In November 2013, FinCEN announced that it was working collaboratively with government and industry partners to close gaps in U.S. regulations that might be exploited by criminals using virtual currencies for illegal activities like money laundering. ${ }^{5}$ In addition to FinCEN, other agencies looking at the regulatory implications of cryptocurrencies include the Securities and Exchange Commission, the Internal Revenue Service, the Federal Election Commission, and the Federal Reserve. ${ }^{6}$

\section{Origin and Operation}

The Bitcoin enterprise started in 2009 based on a computer science research paper by the pseudonymous "Satoshi Nakamoto," an individual or group of individuals that developed complex algorithms the solution of which earns players digital tokens called Bitcoins. ${ }^{7}$ As early users entered the network, they became a part of a decentralised infrastructure that hosts Bitcoin's open-source program. The computers joining the network immediately began capturing virtual coins. The network's protocol was designed to release a new block of Bitcoins every 10 minutes until all 21 million were released, with the blocks getting smaller as time goes on. If the user takes more than 10 minutes to guess the correct code, the Bitcoin program adapts to make the puzzle easier. If the user solves the problems in less than 10 minutes, the code becomes harder.

\footnotetext{
${ }^{1}$ Bank Secrecy Act Regulations - Definitions and Other Regulations Relating to Money Services Businesses, 76 Fed. Reg. 43,585 (July 21, 2011).

${ }^{2}$ Definitions and Other Regulations Relating to Prepaid Access, 76 Fed. Reg. 45,403 (July 29, 2011).

331 U.S.C. $\$ \$ 5311$ et seq.

${ }^{4}$ Financial Crimes Enforcement Network, Application of FinCEN's Regulations to Persons Administering, Exchanging, or Using Virtual Currencies, http://fincen.gov/statutes_regs/guidance/html/FIN-2013-G001.html (last visited June 20, 2014). See generally Thoren-Peden, Park, Pierce, \& Broeker (2013) (analysing FinCEN Guidance).

${ }^{5}$ Alexis \& Ferullo (2013).

${ }^{6}$ Ibid.

${ }^{7}$ This description is based on European Central Bank, Virtual Currency Schemes (2012), available at http://www.ecb.europa.eu/pub/pdf/other/virtualcurrencyschemes201210en.pdf ("Virtual Currency Schemes"), and Popper (2013).
} 
Within this peer-to-peer network, earned Bitcoins can be passed among players and other participants digitally by computer or phone. ${ }^{1}$ Apparently from the very beginning, this decentralised network used Bitcoins as a form of currency in exchange for real-world goods and services from willing providers. $^{2}$ A participant with the necessary free, open-source software can send or receive Bitcoins from other participants, all of whom remain anonymous, ${ }^{3}$ while the Bitcoin itself acts as a digital marker recording the series of trades. ${ }^{4}$

Until the second half of 2013, most Bitcoin origination was done on the individual computers of digital-money fanatics. ${ }^{5}$ However, as the value of a single Bitcoin skyrocketed, the competition for new coins quickly turned into "mining" as an industrial enterprise. Efficiencies were achieved through the use of "miners," specialists that vie to solve algorithms at competitive rates to generate large quantities of Bitcoins. One such mining operation, Cloud Hashing, was profiled in the New York Times in December 2013, "[o]n the flat lava plain of Reykjanesbaer, Iceland, near the Arctic Circle."6 "Reykjanesbaer" "Reykjanesbaer" seems an appropriately mythic-sounding location for the mining of virtual gold. At Reykjanesbaer, high-capacity computers run an open-source Bitcoin program, performing complex algorithms 24 hours a day. If they identify the correct answers before competitors around the world, they win a block of 25 new Bitcoins from the virtual currency's decentralised network. While the network is programmed to release 21 million coins eventually, as of year-end 2013, slightly more than half of the anticipated maximum number of bitcoins was already out in the world. However, since the system is designed to release Bitcoins at a progressively slower rate, the complete mining of all bitcoins could take more than 100 years.

A further important feature has been the emergence of digital exchanges, like Mt. Gox, the largest until its recent collapse. The exchanges operate as secondary markets where persons could buy or sell Bitcoins using conventional currencies, with a fee paid to the respective exchange. ${ }^{7}$

\section{Legal Characterisations}

The emergence of these "conversion" trades - cryptocurrency for conventional currency - has created a critical problem. There is "a growing

\footnotetext{
${ }^{1}$ Virtual Currency Schemes at 21.

${ }^{2} I d$. at 21,24 . It is widely believed that the first commercial transaction in which Bitcoins were used as a means of payment occurred in Jacksonville, Florida, in 2010, when a software programmer named Laszlo Hanyecz exchanged 10,000 Bitcoins in payment for two Papa John's pizzas worth approximately $\$ 30.00$. Bilton (2013). Mr. Hanyecz had "mined" the Bitcoins by solving a series of algorithms set by a Bitcoin mine in Iceland.

${ }^{3}$ Virtual Currency Schemes at 21-23.

${ }^{4} I d$. at 21 .

${ }^{5}$ Popper (2013) at 1.

${ }^{6}$ Popper (2013).

${ }^{7}$ Mt. Gox was sold to a Japanese Bitcoin firm in 2011. Bilton (2013).
} 
trend of real monetary trading ..., the exchange of virtual objects with real currencies," without a clear understanding of the legal nature of cryptocurrencies. Despite the generic way in which cryptocurrencies are often referred to, there are at least three distinct types of arrangements to be addressed. A 2012 study by the European Central Bank (ECB) divides virtual currencies into three categories: (1) closed; (2) unidirectional; and (3) bidirectional. $^{2}$

A closed virtual currency is used exclusively in the internal trade of virtual goods in a virtual world, like the game Monopoly or its online equivalents. ${ }^{3}$ Contextually, the cryptocurrency mimics real-world currency, but without practical or legal consequences.

A unidirectional virtual currency involves a purchase-only framework, in which real-world currency is used to buy a virtual currency or scrip, essentially allowing a prepayment or credit against online purchases of real-world goods or services. ${ }^{4}$ This is very common as a customer-loyalty or advance-revenue device, ${ }^{5}$ as in the case of marketers such as Amazon and Facebook.

A bidirectional virtual currency involves free-flowing interactions between real and virtual contexts. ${ }^{6}$ The interplay between these two contexts raises the possibility of significant fraud or manipulation as transactions flow back and forth across the permeable boundary between the two.

While it is clear that Bitcoin trading is bidirectional, how to characterise, as a legal matter, what is involved in Bitcoin origination and trading remains a critical issue. The outcome of this issue could determine the appropriate regulatory approach, if any, to be taken with respect to cryptocurrencies like Bitcoin. For example, if Bitcoins really are a "virtual currency" - a meaningless phrase, a glib metaphor - then fiscal supervision by the Federal Reserve might be the most appropriate approach to regulating Bitcoin activity. ${ }^{7}$ activity. $^{7}$

However, if they are in any significant sense "currency," then treatment under the U.S. securities regulation framework is categorically ruled out, since "currency" is excluded from the statutory definition of "security." under that characterisation, Bitcoins, at least if involved in a contract for future delivery, would be "commodities" subject to supervision by the Commodity Futures Trading Commission (CFTC). ${ }^{9}$ On the other hand, if we consider the

\footnotetext{
${ }^{1}$ Yang (2013) at 100.

${ }^{2}$ Virtual Currency Schemes at 5.

${ }^{3} I d$. at 13 .

${ }^{4} I d$. at 5 .

${ }^{5}$ Virtual Currency Schemes at 18.

${ }^{6} I d$. at $16-17$.

${ }^{7}$ See Malloy (2011b) at 31-32 (discussing purposes and functions of Federal Reserve).

${ }^{8}$ See, e.g., 15 U.S.C. $\$ 78 \mathrm{c}(\mathrm{a})(10)$ :

The term "security" ... shall not include currency or any note, draft, bill of exchange, or banker's acceptance which has a maturity at the time of issuance of not exceeding nine months, exclusive of days of grace, or any renewal thereof the maturity of which is likewise limited.

${ }^{9}$ Commodity Exchange Act (CEA), 7 U.S.C. § 1a (4). See Commodity Futures Trading Com'n v. International Foreign Currency, Inc., 334 F.Supp.2d 305, 312 (E.D.N.Y. 2004) (holding
} 
term "currency" - undefined in the federal securities and commodities laws as referring only to conventional, government-sponsored currency, then we may need to consider whether the financial obligation represented by a Bitcoin may actually be a form of "note." As a "note," a Bitcoin would be a "security" for certain purposes under the securities laws. ${ }^{1}$

Furthermore, recent news reports have indicated that Bitcoins are beginning to be accepted by more and more vendors as a form of payment. ${ }^{2}$ If in fact it becomes a commonplace that Bitcoins operate as a payment mechanism, then we must deal with the possibility that they should be subject to transactional rules of article 3 of the UCC, and possibly other selected provisions of the Code. It is at this point that we begin to think about the contractual aspects of Bitcoins.

\section{Bitcoins as Property}

At a very elementary level, we could simply characterise Bitcoins as intangible property, worth whatever willing buyers and sellers consider them to be worth. This approach is implicit in the FBI seizure in October 2013 of the assets of Silk Road and its founder, Ross "Dread Pirate Roberts" Ulbricht, on hacking, money laundering and narcotics trafficking charges. ${ }^{3}$ Silk Road was an Internet site that hosted anonymous, Bitcoin-based drug and gun sales. The seized assets included one of the world's largest accumulations of Bitcoins, a portion of which were publicly auctioned on 27 June 2014 as property of a criminal enterprise. ${ }^{4}$ The obvious difficulty that results from this characterisation is that there will be no clear and consistent institutional setting within which to determine valuation, outside of specific transactions.

Within specific transactions, however, one would have a very concrete measure of the value of the Bitcoin. For example, in March 2014 the U.S. Internal Revenue Service released guidance indicating that it would treat Bitcoin and other cryptocurrencies as property for tax purposes, not as currency. ${ }^{5}$ As a result, determinations of income and valuation would apply rules that govern stocks and barter transactions. If this logic is followed consistently, Bitcoins held for more than a year and then sold or traded would pay significantly lower capital gains tax rates, as opposed to rates applicable to ordinary income. Likewise, in a falling Bitcoin market, losses from sales of or trades involving Bitcoins held for more than a year could be deducted from

\footnotetext{
that "currency is a commodity as defined under the CEA" and that currency transactions "for future delivery" fall within the CEA).

${ }^{1}$ Reves v. Ernst \& Young, 494 U.S. 56 (1990) (holding that notes that are subject of common trading and bear a "family resemblance" to securities fall within definition of "security" for purposes of federal securities laws).

${ }^{2}$ In December 2013, Overstock.com, a major online discount retailer, announced that it would begin accepting Bitcoin within the next six months. Wingfield (2013).

${ }^{3}$ Fingas (2013).

${ }^{4}$ Cooper (2014).

${ }^{5}$ Notice 2014-21, 'IRS Virtual Currency Guidance,' Internal Revenue Bulletin 2014-16 (April 14, 2014), available at http://www.irs.gov/irb/2014-16_IRB/ar12.html (last visited June 23, 2014). See Rubin \& Dougherty (2014) (discussing implications of IRS guidance).
} 
capital gains, but only up to $\$ 3,000.00$ in such losses could be deducted from ordinary income.

\section{Bitcoins as Securities}

One obvious alternative is to characterise Bitcoins as securities, subject to the federal securities laws. ${ }^{1}$ In 2013 article, Ruoke Yang argued that unorthodox settings like Bitcoins should be treated as "investment contracts," one identified type of "security" in the definition of the term within the federal securities laws. ${ }^{2}$ This is subject to a three-factor test adopted by the U.S. Supreme Court in the classic case SEC v. W.J. Howey Co. ${ }^{3}$ The Court interpreted the term "investment contract," undefined by the statute, to mean "a contract, transaction or scheme whereby a person invests his money in a common enterprise and is led to expect profits solely from the efforts of the promoter or a third party" 4 The first factor - an investment of money - seems easily met in the case of the Bitcoin, since it is a bidirectional cryptocurrency. ${ }^{5}$

Second, the investment must be in a common enterprise, and this is where Yang's analysis becomes problematic. The anonymous peer-to-peer nature of the network, and the fact that there is no enterprise to which Bitcoin value relates may make any notion of a common enterprise a difficult one to sustain. As Yang notes, the cases themselves are not particularly consistent in their approaches to interpreting "common enterprise." Cases often take off in quite disparate directions, looking for "horizontal" relationships among investors or "vertical" relationships between investors and promoter. ${ }^{7}$ The problem with cryptocurrencies like the Bitcoin would seem to be that the relationships, horizontally or vertically, are too disparate and individualised to support commonality.

This observation leads to a critical problem for the third factor underlying the "investment contract" concept, the requirement that there be an expectation

\footnotetext{
${ }^{1}$ See generally Yang (2013) (considering arguments that Bitcoins are securities).

${ }^{2} 15$ U.S.C. $\S 77 b(a)(1)$ (“The term 'security' means any . . investment contract. ..").

328 U.S. 293 (1946).

${ }^{4}$ W.J. Howey Co., 328 U.S. at 298.

${ }^{5}$ I am sceptical, however, of Yang's alternative argument that "investment" of electricity would constitute an "investment of money" for these purposes. (See Yang (2013) at 109-110). At best, this would probably represent a commodity trade, but in any event the argument is unnecessary, given the bidirectional nature of the Bitcoin itself. Yang recognises this later, in observing:

Note that this result would apply to other virtual currencies in the bidirectional and unidirectional categories that normally would only require real currencies in exchange for virtual currencies. Here, the case with Bitcoin is even stronger than most virtual worlds that allow bidirectional RMT [i.e., "real money trading"] because whereas some users in Second Life may argue that their interests do not require them to participate in the RMT exchange, all users in Bitcoin engage in bidirectional RMT the alternative currency purpose of Bitcoin.

Yang (2013) at 110-111 (footnotes omitted).

${ }^{6}$ See, e.g., W.J. Howey Co., 328 U.S. at 301.

${ }^{7}$ See, e.g., SEC v. ETS Payphones, Inc., 300 F.3d 1281 (11th Cir. 2002) (concerning horizontal commonality); SEC v. Eurobond Exch., Ltd., 13 F.3d 1334 (9th Cir. 1994) (concerning vertical commonality).
} 
on the "investor's" part that profits will be derived solely from the efforts of the promoter or third parties. Again, the disparate, peer-to-peer nature of the Bitcoin network would seem to presuppose the active participation of those involved, not a passive reliance on the efforts of third parties. ${ }^{1}$

While we may have doubts about the legal argument that cryptocurrencies are "securities," there is little doubt that swaps and derivatives contracts based on these currencies - arrangements that are a near reality already ${ }^{2}$ - would themselves be classifiable as securities or commodities subject to regulation and disclosure requirements. ${ }^{3}$

\section{Bitcoins as "Currency"}

The Securities Exchange Act of 1934 expressly excludes from the definition of the term "security" for purposes of the act "currency or any note, draft, bill of exchange, or banker's acceptance which has a maturity at the time of issuance of not exceeding nine months, exclusive of days of grace, or any renewal thereof the maturity of which is likewise limited." ${ }^{4}$ The term "currency" is not defined by the securities laws. Cryptocurrency or "virtual currency" has commonly been characterised as "a medium of exchange without government backing that can be circulated over the Internet," but one might reasonably argue that the term "currency" ought to be read as referring only to conventional, government-sponsored currency.

Consider, for example, a December 2013 notice issued jointly by the People's Bank of China (PBOC) - China's central bank - and the Ministry of Industry and Information Technology, the China Banking Regulatory Commission, the China Securities Regulatory Commission, and the China Insurance Regulatory Commission that has banned financial and payment institutions from using Bitcoin. ${ }^{6}$ This is a very significant development, for two two reasons. First, the notice is an official response to the cryptocurrency phenomenon by the country with arguably the largest Bitcoin trading volume in the world, with multiple trading platforms, including BTA China, China's largest Bitcoin trading platform.

Second, it represents a decisive choice to regulate Bitcoin trading as private transactional activity and to reject the characterisation of Bitcoin as a currency, "virtual" or otherwise. The notice requires Bitcoin trading platforms

\footnotetext{
${ }^{1}$ Cf., e.g., ETS Payphones, Inc., 408 F.3d 727 (1 $1^{\text {th }}$ Cir. 2002) (emphasizing essential managerial efforts of placement, collection and maintenance of products).

${ }^{2}$ See Leising \& Brush (2014) (describing the development of Bitcoin swaps).

${ }^{3}$ It is reported that the Commodities Futures Trading Commission is already considering appropriate regulatory measures to govern such instruments as commodities. Leising \& Brush (2014).

${ }^{4} 15$ U.S.C. $\$ 78 \mathrm{c}(\mathrm{a})(10)$.

${ }^{5}$ Alexis \& Ferullo (2013).

${ }^{6}$ PBOC, Yin Fa [2013] No. 289, Notice on Guarding Against Bitcoin Risks, available at http://www.pbc.gov.cn/publish/goutongjiaoliu/524/2013/20131205153156832222251/2013120 5153156832222251_html (in Chinese). See Pappas, L.A. (2013) (discussing PBOC notice on Bitcoin use).

${ }^{7}$ Pappas (2013).
} 
to register with Chinese telecommunications regulators. ${ }^{1}$ At the same time, the notice takes the explicit position that "Bitcoin is not issued by monetary authorities, is not the same as legal tender, and is not in any real sense an actual currency.[ . . ] Since Bitcoin does not have a legal status or monetary equivalent, it cannot and should not be used as a currency in the market." ${ }^{2}$

In contrast, in an interesting development, in May 2014 Spanish tax authorities indicated that they are monitoring the evolution of cryptocurrencies, given their potential use for money laundering. ${ }^{3}$ Without clearly identifying Bitcoin as either currency or property, the Government stated in response to a parliamentary query, that the $€ 2,500$ limit placed on cash transactions could apply to Bitcoin transactions. ${ }^{4}$

\section{Bitcoins as Consumer Transactions}

One approach that seems to be favoured by some U.S. jurisdictions is to treat cryptocurrencies as consumer transactions. ${ }^{5}$ Indeed, the only concrete step step taken so far at the state level in the United States has been the issuance of consumer-oriented "guidance" by the North American Securities Administrators Association and the Conference of State Bank Supervisors in April 2014. ${ }^{6}$ While not mandatory in any sense, the Model State Consumer and and Investor Guidance on Virtual Currency offers suggestions to state regulators in informing consumers about virtual currency. Consumers should be advised to consider, when trading or investing in virtual currencies, that virtual currencies may be unregulated; that they can be stolen or otherwise subject to cybercrime; $;^{7}$ that they are volatile in value; that they have been connected to criminal activities; and, that virtual currency transactions may be taxable.

\section{Conclusion}

Until its own collapse amid fraud charges, Mt. Gox was a trading website for Bitcoins ("btc"). It provided public and readily accessible trading data that reflected Bitcoin market performance.

How have Bitcoins been performing? We have been running a modest empirical test, beginning Christmas morning 2013. (See Figure 1, reproduced below.) One curious feature is that trading in Bitcoins appears to have two spikes per day, perhaps reflecting the extended trading patterns in the "currency," unconstrained by traditional market structures. At least until the

\footnotetext{
${ }^{1}$ Id.

${ }^{2}$ Pappas (2013).

${ }^{3}$ King (2014).

${ }^{4} I d$.

${ }^{5}$ Kessler (2014).

${ }^{6}$ Model State Consumer and Investor Guidance on Virtual Currency, http://www.csbs.org/ legislative/testimony/Documents/ModelConsumerGuidance--Virtual\%20Currencies.pdf.

${ }^{7} \mathrm{~A}$ key risk is that Bitcoins are essentially computer files that can be stolen by hackers. Alexis (2013).
} 
collapse of Mt. Gox, the values had been steadily cumulating from day to day. 
Figure 1. Bitcoin Market Performance: Empirical Test (as of 1 Jan 2014)

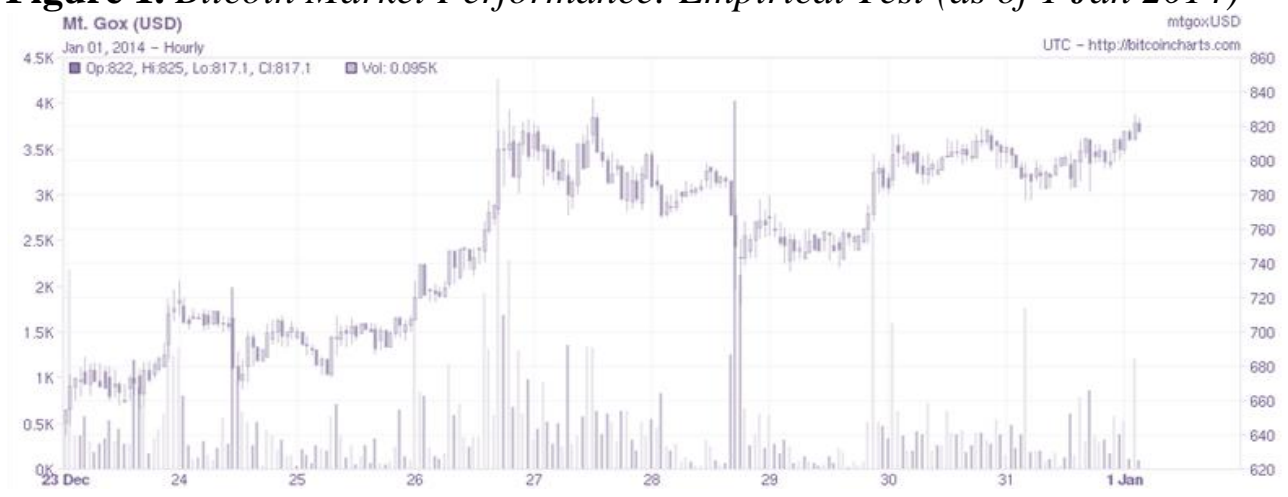

The gains reached as high as 15.15 percent, ${ }^{1}$ prior to the market adjustment that resulted from the collapse of Mt. Gox. The performance tends to flatten out when you look at a longer trading period, for example six months to the past year. (See Figure 2, reproduced below.) However, from the time that Bitcoin trading began attracting news coverage - roughly, from the Fall 2013 forward - the appreciation in value markedly increased. What is as yet unclear is the extent to which, if at all, these dramatic gains reflect market manipulation in Bitcoin trading. ${ }^{2}$ Indeed, it is conceptually challenging to consider what manipulation would mean in this context.

Figure 2. Longer term Bitcoin Performance

60

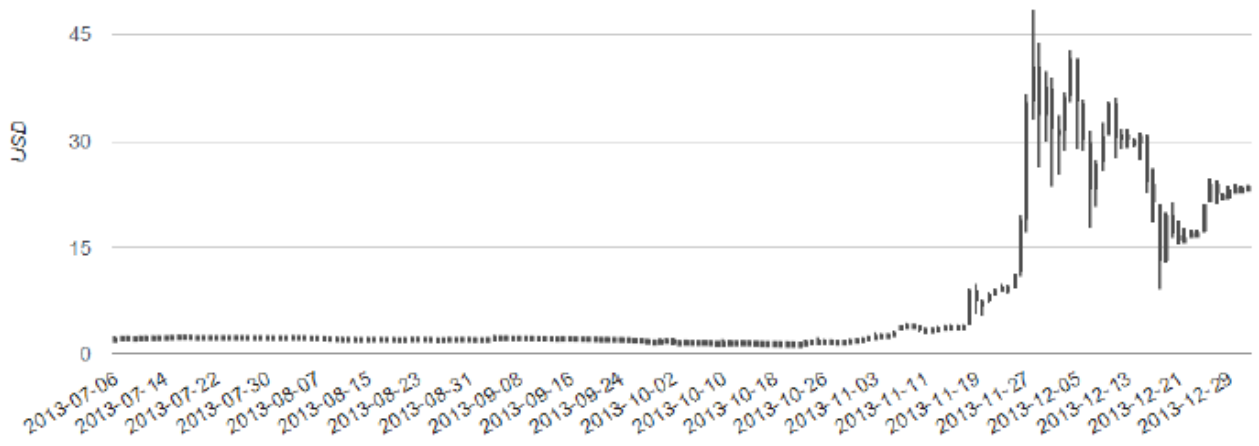

Source: LTC/USD 6-months Chart from BTC-e

We may never have a complete answer to that question. Mt. Gox, the Tokyo-based Bitcoin exchange, filed for bankruptcy in Japan in February 2014 after disclosing that it could not account for approximately 850,000 Bitcoin units, including more than 700,000 units belonging to its customers. ${ }^{3}$ (While

\footnotetext{
${ }^{1}$ On the downside, these gains may have been greater, but for the fact that my technical adviser periodically liquidated incremental gains from the account. On the upside, this practice protected us from greater account losses as the market decreased dramatically after the collapse of Mt. Gox.

${ }^{2} C f$., e.g., 15 U.S.C. $\S 78 \mathrm{i}$ (prohibiting manipulation of securities markets).

${ }^{3}$ Harris (2014).
} 
Mt. Gox has since announced that approximately 200,000 Bitcoins had been located, customer losses still exceed \$218 million.) Parallel suits were brought in the United States by U.S. customers against the company's U.S. affiliate, Mt. Gox principal Mark Karpeles, another company controlled by him, and other Mt. Gox insiders, as well as Mizuho Bank Ltd., the Japanese bank that processed transactions for the exchange. Whether the "losses" were the result of gross negligence or fraud, ${ }^{1}$ these recent events underscore the need for clear transactional and regulatory frameworks appropriate to the Bitcoin context. For example, treating the financial obligation represented by the Bitcoin variously as either an "investment note" where it is investment-motivated, and thus subject to the protections of the securities laws, or a "commercial note" where it is motivated by short-term commercial or transactional objectives, and subject to ordinary principles of contract and payment laws. Such nimble treatment is essential if cryptocurrency regimes are to be more than an e-tulip mania, ${ }^{2}$ a whimsical curiosity of the Internet age.

\section{References}

Alexis, A. (2013). 'Bitcoin Seen Facing Big Hurdles As Supporters Seek Wide Adoption', BNA Banking Daily (Dec. 2, 2013), available at http://bna/com (last visited June 20, 2014).

Alexis, A. \& M. Ferullo (2013). 'Virtual-Currency Oversight Is High Priority, Officials Say' BNA Banking Daily (Nov. 19, 2013), available at http://bna/com (last visited June 20, 2014).

Bilton, N. (2013). 'Betting on a Coin With No Realm,' N.Y. Times, Dec. 23, 2013, at B8.

Cooper, D. (2014). 'US to begin selling off its Silk Road Bitcoin hoard' at: http://ww w.engadget.com/2014/06/13/us-silk-road-Bitcoin-auction/?ncid=rss truncated\&c ps=gravity (last visited June 20, 2014).

Fingas, J (2013). FBI seizes black market website Silk Road, arrests its founder, available at http://www.engadget.com/2013/10/02/fbi-seizes-black-market-site-silkroad/ (last visited June 1, 2014).

Garber, P.M. (1989). 'Tulipmania,' Journal of Political Economy 97:535-560.

Harris, A. (2014). 'Mt. Gox's U.S. Customers Ask Judge To Approve Deal to Revive Bitcoin Exchange,' BNA Elec. Comm. \& L. Rep. (May 7, 2014), available at http://www.bna.com (last visited June 20, 2014).

Kessler, M. (2014). 'States Seek Approach to Protect Consumers While Allowing Innovation in Virtual Currency' BNA Banking Daily (April 25, 2014), available at http://www.bna.com (last visited June 20, 2014).

King, B.A. (2014). 'Spain Eyes Bitcoin-Based Fraud; Stops Short of Cash Treatment for Now,' BNA Elec. Comm. \& L. Rep., available at http://www.bna.com (last visited May 28, 2014).

\footnotetext{
${ }^{1}$ See generally McAuley (2014) (reporting on claims resulting from failure of Bitcoin exchange).

${ }^{2}$ On the 1637 tulip investment bubble and the crash that followed, see Garber (1989).
} 
Leising, M. \& S. Brush (2014). 'Bitcoin Swaps Near Reality As Tera Creates Legal Framework,' BNA Elec. Comm. \& L. Rep. (Mar. 26, 2014), available at http://www.bna.com (last visited June 20, 2014).

Malloy, M.P. (2011). Banking and Financial Services Law 3d ed. Durham: Carolina Academic Press.

Malloy, M.P. (2011). Principles of Bank Regulation 3d ed. St. Paul: West.

McAuley, D. (2014). 'Mt. Gox Bitcoin Exchange Accused of Fraud, Negligence in Putative Class Action Lawsuit,' BNA Elec. Comm. \& L. Rep. (Feb. 28, 2014), available at http://www.bna.com (last visited June 4, 2014).

Pappas, L.A. (2013). 'China Bans Bitcoin Bank Transactions, Internet Use Allowed' BNA Int'l Bus. \& Fin. Daily (Dec. 6, 2013), available at http://www.bna.com (last visited June 20, 2014).

Popper, N. (2013). 'Into the Bitcoin Mines,' N.Y. Times, Dec. 22, 2013, at BU 1.

Rubin, R. \& C. Dougherty (2014). 'IRS Says Bitcoin Is Property, Not Currency, in U.S. Tax System' BNA Banking Daily, (Mar. 26, 2014), available at http://www.bna.com (last visited June 4, 2014).

Thoren-Peden, D.S., Park, J., Pierce, A.L. \& E.S. Broeker (2013). 'Financial Crimes Enforcement Network Issues Guidance on Virtual Currency,' Banking L.J. 130:579-583.

Turbeville, W.C. (2013). 'A New Perspective on the Costs and Benefits of Financial Regulation: Inefficiency of Capital Intermediation in a Deregulated System' Maryland L. Rev. 72:1173-1203.

Wingfield, N. (2013). 'Overstock.com, Signaling Mainstream Support, Plans to Accept Bitcoin,' N.Y. Times, Dec. 27, 2013, at B3.

Yang, R. (2013). 'When Is Bitcoin a Security Under U.S. Securities Law?' Journal of Technology Law \& Policy 18:99-129. 
y 2015 